\title{
UNA VISIÓN DEL INDIO MEXICANO EN EL SIGLO XVII \\ Manuel Olimón*
}

...puedo volver a asegurar a Vuestra Majestad que si hay en el mundo (hablo de los efectos de la naturaleza y no tratando de los de la gracia) mansos y humildes de corazón, son los indios, y que estos naturalmente parecen los que aprenden del Señor cuando dijo:

Que aprendamos de su Divina Majestad a ser mansos y humildes de corazón.

(Don Juan de Palafox, Obispo de Puebla escribe al Rey, 1640 -?-)

\section{Acercamiento a una huella antigua}

La opinión que unos hombres expresan sobre otros, es uno de los datos más delicados y profundos con los que el historiador cuenta para su trabajo de desentrañar y reconstruir el pasado. Es dato delicado, frágil, porque el riesgo de equivocaciones, de paso del egoísmo, de falta de consideración de conjunto, puede viciarlo. Pero es también profundo, porque se suele dejar impresa una huella que en el futuro ayudará más para la comprensión de las realidades

${ }^{*}$ Universidad Pontificia, México. 


\section{Manuel Olimón}

humanas, de la interioridad vertida sobre la vida, de la conciencia y la decisión de los antepasados en la fisonomía de los pueblos.

En las páginas que siguen, trataré de reconocer una realidad social del siglo XVII novohispano. Dentro de ella, buscaré los condicionamientos que de alguna manera influyeron en la evangelización de entonces. Ella no era ya el anuncio primero, incitador de la fe, creativo y novedoso, sino un quehacer que suponía el asentamiento prolongado de una estructura cultural. Descubriremos, más en concreto, la opinión que de los indígenas mexicanos de entonces se formó un destacado representante de la cultura, de la política y de la pastoral en ese siglo, Don Juan de Palafox y Mendoza, acotándolo brevemente con otro opinante, apasionado y culto, Don Carlos de Sigüenza y Góngora.

La opinión global, diversificada y madura que se reconoce en ellos, contribuye no sólo a obtener una imagen de las maneras de juzgar entonces a los indios, sino que ayuda a percibir huellas que han superado las barreras de ese siglo y han penetrado en el ser de México.

Voy a utilizar como material de trabajo principalmente un escrito publicado por su autor en el propio siglo XVII. Se trata de un texto titulado De la naturaleza del indio, redactado por el obispo de Puebla de los Ángeles como informe al Rey después de la visita a él encomendada a la Nueva España. Haré referencia también en una parte de este escrito, al Alboroto y motín de los indios de México, título con que se publicó una carta de Sigüenza al Almirante Andrés del Pez en 1692. ${ }^{1}$

La riqueza de estos testimonios es indudable y su orientación interior penetra con profundidad y ofrece un retrato bastante bueno de la realidad del indio en la sociedad barroca de la Nueva España. ${ }^{2}$

${ }^{1}$ Utilizo las versiones facsimilares: Mantal de estados y profesiones. De la naturaleza del indio (Biblioteca mexicana de escritores políticos), UNAM/Miguel Ángel Porrúa, México, 1986, p. 47-97. Teatro de virtudes políticas. Alboroto y motín de los indios de México (Biblioteca mexicana de escritores políticos), UNAM/MAP, México, 1986, p. 149-215.

${ }^{2}$ En cierta manera este texto continúa lo que escribí sobre el Manual de estados y profesiones: Perfil ideal del hombre cristiano en la Nueva España del siglo XVH, EfMex. 7/20, 1989, p. 225-242. 


\section{UNA VISIÓN DEL INDIO MEXICANO}

$\mathrm{Al}$ ir leyendo la larga carta palafoxiana e incluso al compararla con la misiva de Sigüenza y Góngora, van apareciendo delante de los ojos cuadros diversos, pero que reflejan con tonalidades complementarias el ser de una raza enmarcada en un ambiente en el que sus decisiones se encontraban subordinadas a las decisiones de los "mayores" (los españoles) y en el que la religiosidad no siempre era congruente con la conducta moral.

Contemplar estos cuadros escritos, no pintados, es contemplar un mundo que desfila ante nosotros como una galería viva y que toca nuestro ser nacional y cristiano. Las grandes gestas de la historia, la evocación de las obras monumentales y de las hazañas de la evangelización, se matizan y comprenden con mayor hondura a través de estos pequeños asomos al asombroso ser interior del hombre de otros tiempos. Así como la vida nuestra tiene infinitamente más momentos de cotidianidad y de mediana relevancia, la vida de los pueblos se integra con el gozo y el sufrimiento cotidiano, con la expresión de la bondad amable, de la hospitalidad sincera, de la justicia y la humilde industria, pero también con las carencias y negligencias, el rencor guardado y rumiado y el odio que en un momento se desborda. Sobre esta realidad, que totaliza la materia humana, se viene a anunciar el evangelio, se derrama el agua del bautismo y se celebra la eucaristía, vivo memorial de la muerte y resurrección de Cristo.

\section{Observación palafoxiana de los indios de México}

Don Juan de Palafox motiva su exposición en el deber y la experiencia suyas en la Nueva España y en la necesidad del amparo y la protección del Rey hacia los indígenas. Ha sido -lo recuerda-Fiscal de Indias por más de veinte años, "cuyo oficio principal es ser protector de indios", ${ }^{3}$ ha ejercido por disposición real el cargo de Visitador General del Reino novohispano, para lo cual se ha encontrado con un buen número de

${ }^{3}$ De la naturaleza del indio, 48 (paginación de acuerdo a la edición de 1986). En adelante citaré únicamente la página. 


\section{Manuel Olimón}

dificultades. ${ }^{4}$ Pero fundamentalmente ha sido obispo y en el ejercicio del cuidado pastoral de la grey, ha conocido los múltiples males que se ciernen sobre los indios.

Aquello que por ser fiscal o visitador se le ha ocultado, ha aparecido a la luz en su quehacer pastoral. Dice "...es más a propósito para conocer estos daños (aunque no para castigarlos) el oficio de prelado y pastor, el cual como por su ocupación se ejercita en apacentar sus ovejas, verlas y reconocerlas, llamarlas, enseñarlas y buscarlas por los pueblos y los montes, (pues) no se recatan los interesados ni los lastimados tanto como del juez o visitador, porque siempre hablan al prelado con la confianza de padre". 5

Esas noticias, esos "daños", conocidos por el trato con los indígenas de su diócesis, que "llega a tener casi la cuarta parte de todo el distrito de - aquella Real Audiencia de México", ${ }^{6}$ requieren atención delicada del Rey y del gobierno, la concreta insistencia en el cumplimiento de las leyes, muchas de las cuales, a pesar de contener excelentes prescripciones en su letra, en la práctica es vano su cumplimiento: "...ofreceré a Vuestra Majestad...los motivos que están solicitando la clemencia de Vuestra Majestad y el santo celo de sus ministros, (para) que animen estas leyes y las vivifiquen con su misma observancia... Porque las leyes sin observancia, Señor, no son más que cuerpos muertos arrojados a las calles y plazas, que sólo sirven de escándalo de los reinos y ciudades y (con los) que tropiezan los vasallos y ministros con la trasgresión, cuando habían de fructificar (siendo) observadas y vivas (en) la conservación, alegría y tranquilidad de esos mismos reinos y ciudades".

Presentará en su escrito las dificultades por las que pasan los indios y propondrá, sacándolos de su experiencia, los "remedios que pueden aplicarse a esos daños". 8 Pero de manera principal enunciará los valores de esos "utilísimos y fidelísimos vasallos de las Indias" que son los indíge-

${ }^{4}$ Cf. 50 .

5 50s. (Ortografía modernizada y, cuando pareció necesario para la comprensión, ligeramente modificada.)

${ }^{6} 48$.

751 .

${ }^{8} 52$. 
nas. Propone: "...me ha parecido que era buen medio proponer a Vuestra Majestad las calidades, virtudes y propiedades de aquellos utilísimos y fidelísimos vasallos de las Indias y describir su condición sucintamente y referir sus méritos, proque todo esto hace en ellos más justificada su causa y en Vuestra Majestad más heroica y noble la razón de su amparo". 9

La primera buena impresión que se tiene de los indios es cuando se reconoce su religiosidad. Ésta se muestra en la dedicación al culto, tanto en lo público como en sus casas, en el fervor que muestran en los actos religiosos, en actitudes de penitencia y de acercamiento a los sacramentos, así como en la manera con la que contribuyen al sustento de los ministros de la Iglesia.

Si en algo son espléndidos y pródigos estos hombres es precisamente en este punto. Dice Palafox: "No hay casa por pobre que sea, que no tenga su oratorio, que ellos llaman 'santo calli', que es 'aposento de Dios y de los santos', y allí tienen puestas sus imágenes, y cuanto pueden ahorrar de su trabajo y sudor, lo gastan en estas santas y útiles alhajas, y aquel aposento está reservado para orar en él y retirarse cuando comulgan, con grandísima reverencia y silencio." ${ }^{10}$

Juzga, a partir de las actitudes observadas, la profundidad que debe tener la fe cristiana en ellos: "La piedad en el culto divino, en que se explica la viva fe que en los indios vasallos de Vuestra Majestad está ardiendo, es grandísima." ${ }^{11}$ Da a conocer su experiencia: "...si no es que en alguna parte, por falta de doctrina y de ministros haya alguna superstición, es cierto que en todas las demás de este Nuevo Orbe, son increíbles, Señor, las demostraciones que los indios hacen de muy fervorosos cristianos, como se ve en las cosas... que yo mismo he mirado y tocado con las manos". 12

Es notable el trato que se tiene de parte de ellos hacia los pastores de la Iglesia. Observa: "...La humildad y el respeto, Señor, con que tratan a sus ministros y prelados... es admirable, besándoles las manos con gran 
Manuel Olimón

reverencia... allanándoles los caminos cuando van a sus visitas, previniéndoles comida, jacales y enramadas para su descanso y procurando agrandarles en todo con una solicitud y ansia atentísima".

Concluye esta parte de su escrito afirmando con superior optimismo: "...dudo mucho que haya religión tan perfecta y observante que este exterior culto con mayor humildad lo ejercite y ofrezca". ${ }^{14}$

\section{La virtud de base en el indio mexicano}

Una larga motivación para recibir la protección del Rey hacia los indígenas, está basada sobre todo en la forma como ellos llegaron a ser súbditos de la Corona: sin gran costo y trayendo sus tierras innumerables bienes para el engrandecimiento del Reino español. Palafox describe con vivo realismo el caudal económico que esto ha significado: "Así como los indios son (los) vasallos que menos han costado a la Corona, no son los que menos la han enriquecido y aumentado. Porque no puede dudarse que muchos de los demás reinos de Vuestra Majestad y de otras coronas

42 que hay en el mundo, aunque se consideren juntas, no igualan ni llegan a la menor parte de los tesoros que en tan breve tiempo ha fructificado la Nueva España en las minas del Potosí, Zacatecas, el Parral, Pachuca, Guanajuato y otras y en el tributos, alcabalas, tercios de oficios y diversos géneros de rentas..." 15

La conquista de México, situada en tiempos de Palafox a más de ciento veinte años de distancia, trajo como consecuencia el asentamiento de la autoridad española en tierras americanas, un asentamiento que, por la poca resistencia de los indígenas, es juzgado como sencillo, fácil y "voluntario".

En un párrafo que podemos hoy considerar discutible, explica la doctrina común en su época acerca de la legitimidad de la conquista y del posterior dominio español sobre las Indias. Escribe: "Porque como

$1358 \mathrm{~s}$

14 59. "Religión" está usada en el sentido de "orden o congregación religiosa". 1567 . 


\section{UNA VISIÓN DEL INDIO MEXICANO}

quiera que en sus principios no entraron en la corona real por herencia u otro de los comunes derechos, sino por elección de ellos mismos, (pues) voluntariamente se sujetaron al Señor Emperador Carlos V y por la aplicación de la Apostólica Sede a la corona de Vuestra Majestad por altísimos motivos y una justa conquista y jurídica acción para introducir estas almas en la Iglesia y apartarlas de muchas idolatrías, sacrificios humanos y otras barbaridades que les enseñaba el demonio a quien servían. Y como quien para sacarlos de aquella durísima esclavitud los traía al suave dominio de Vuestra Majestad, y de (ser) hijos de ira y de indignación, por este medio los reducían sus católicas armas a la libertad de hijos de la Iglesia y a gozar del honor de ser vasallos de su católica y religiosísima corona y de una excelsísima y devotísima casa como la de Austria. Claro está (pues), que es muy loable y ponderable y que pone en grave obligación a Vuestra Majestad el haber hallado a estos naturales tan fáciles y dóciles a este bien y tan suaves a inclinar la cabeza al yugo de la real dignidad y jurisdicción." 16

Reconoce el obispo poblano que, a pesar de la facilidad con la que se impuso el gobierno hispánico en México, los indios no fueron en el momento de la conquista y en los años posteriores, gente cobarde, ruin o de poca fuerza, sino gente valiente y esforzada. Tituló al capítulo IV de su carta, "Del valor y esfuerzo de los indios y que su lealtad y rendimiento a la Corona de Vuestra Majestad no procede de bajeza de ánimo sino de virtud." ${ }^{17}$ Ejemplifica: "...en México se defendieron (ante los españoles) tres meses, ya muy desamparados... con grandísimo valor, y hacièndo sus asechanzas y emboscadas, y engañando en ellas a soldados tan experimentados como Hernando Cortés y los suyos, padecieron increíble hambre y trabajos con grandísima fortaleza de ánimo. El último

${ }^{16} 60$. Acerca de la legitimación de la conquista, es de primera importancia el texto de Fray Alonso de la Vera Cruz, De dominio infidelium et iusto bello, de 1554. Cf. mi artículo: Fray Alonso de la Vera Cniz. Una reflexión teológica frente a su tiempo, EfMex 2/5, 1984. Un amplio estudio sobre el asunto del Imperio y el Papado: W.D. McCready, The problem of the Empire in Augustinus Triumphus and late medieval papal hierocratic theory, Traditio 30 (1974), p. 325-349.

${ }^{17} 62$. 


\section{Manuel Olimón}

rey llamado Guatemuz (sic), con ser de edad de veinticuatro años, después de haber defendido la ciudad con increíble constancia y fortaleza, cuando vió que ya no tenía gente, luego que retirándose le cogieron y llevaron a Hernando Cortés, perdida del todo su corona, tendido delante de él, se veía cautivo y le dijo: 'Toma este puñal -sacándole de su lado-y mátame': como quien dice que sin imperio y libertad ya le sobraba la vida." 18

\section{El indio inocente y pobre}

Don Juan de Palafox pone como punto de enlace de las virtudes indígenas, lo que él titula "inocencia" y que define del modo siguiente: "La inocencia es una privación de vicios y pasiones consentidas que en su raíz hace a los hombres admirables y por sus efectos y pureza de vivir, amables y dignos de protección con los reyes y superiores."

Distribuye las áreas de las que procede esa inocencia, estableciendo cuán ajena es -"comúnmente"- a la raza indígena la codicia, la ambición, la soberbia, la ira y la envidia y, por el contrario, cómo está enraizada la humildad. $^{20}$

Hacia la conclusión del capítulo VI de su misiva, anuda las frases al respecto en un extenso párrafo que al lector moderno puede traerle la idea de inmovilismo y pesimismo, sobre todo por lo que expresa de que "ni aspiran más que a vivir y que se olviden de ellos". Leamos este párrafo: "...ellos no conocen la envidia porque no conocen la felicidad ni hacen caso de ella, ni aspiran más que a vivir y que se olviden de ellos. Y como quiera que su ambición es ninguna, no puede ser alguna su envidia, ni los deseos los inquietan a tener más (que) aquello que les dan, ni les afligen o entristecen ajenas dichas, porque no llegan a prenderlas y procurarlas. Están remotísimos de juramentos, blasfemias, murmuraciones, juegos y prodigalidad, vicios tan frecuentes en otras naciones,

1863 s.

1969.

${ }^{20}$ Cf. 69-71. 


\section{UNA VISIÓN DEL INDIO MEXICANO}

porque los de este género no se hallan sino en muy raros de los que habitan aquellas dilatadas provincias. Mande Vuestra Majestad, le suplico, ver si nación que está por la mayor parte exenta de vicios tan capitales... puede llamarse más inocente que las otras..."21

Si alguna característica revela la condición del indio más que alguna otra, se trata sin duda de su pobreza, de la que no puede decirse sino que es evangélica y apostólica: "...siguen a la letra el consejo de San Pablo y lo que el santo quiso para sí, cuando dijo: "En teniendo con qué cubrir nuestros cuerpos y con qué alimentarnos, todo lo demás nos sobra." 22

La pobreza del indio es, incluso, modelo de pobreza religiosa y franciscana. Refiere: "He oído decir a algunos religiosos de la seráfica orden de San Francisco... que si aquel seráfico fundador, tan excelente amador de la pobreza evangélica hubiera visto a los indios, de ellos parece que hubiera tomado alguna parte del uso de la pobreza, para dejarla a sus religiosos por mayorazgo y para que sirviese a la evangélica, que él escogió." 23 Y hace referencia a la tradición de que a un religioso franciscano que ejercía su ministerio en el obispado de Puebla le dijeron Santa Clara y San Francisco: "Los indios ejercitan la pobreza, obediencia y paciencia, que vosotros profesáis." 24

De esa pobreza del indio se sostienen en las Indias tanto la Iglesia como el Estado. Escribe el obispo: "...su desnudez, pobreza y trabajo sustentan y edifican las iglesias, hacen mayores sus rentas, socorren y enriquecen las religiones y a ellos se debe gran parte de la conservación de lo eclesiástico. Y (en) cuanto a lo secular, su trabajo fecunda y hace útiles las minas, cultiva los campos, ejercita los oficios y artes de la república, hace poderosos los de justicia, paga los tributos, causa las alcabalas, descansa y alivia a los magistrados públicos, sirve a los superiores, ayuda a los inferiores, sin que haya cosa alguna, desde lo alto hasta

2171.

22 Cita el texto latino: "Habentes, alimenta et quibus tegamur, his contenti sumus" (1 Tim. 6,8), y en seguida traduce. 75.

2374.

24 75. Texto latino: Indi paupertatem, et oboedientiam et patientian quam vos professi estis exercent. 
Manuel Olimón

lo bajo, en que no sean los indios las manos y los pies de aquellas dilatadas provincias y si se acabaran los indios, se acabarían del todo las Indias, porque ellos son los que las conservan... y como abejas solícitas labran el panal de miel para que otros se lo coman." ${ }^{25}$

El cuadro que Palafox pinta de esta humildad interior del indio, no deja de ser también el retrato de la externa injusticia que se veía por todos los horizontes de la Nueva España y que tenía como blanco principalmente a la masa indígena. Una velada alusión a la falta de compromiso evangélico de las órdenes religiosas y de conformación a su primitivo espíritu, descubre al obispo que, en sus escritos y acciones se revela como deseoso de una profunda reforma de la Iglesia.

\section{El indio paciente, magnánimo, parsimonioso y obediente}

En la enumeración de los elementos que constituyen la condición virtuosa del indio mexicano, es Palafox extenso y pródigo en calificativos. La paciencia es continuación a lo largo del tiempo, de la humildad del indígena, humildad sometida a prueba prolongada por la relación constante con los demás miembros de la sociedad, que no pocas veces llegan al abuso con ellos.

Pone ejemplos y califica al indio con el título del evangelio, "humildes y pobres de corazón": "Si le dice a un indio un negro que va cargado que tome aquella carga que él lleva y se la lleve, y sobre eso le da golpes y le aflige de injurias... toma la carga y los golpes y los lleva con paciencia... ellos son en mi sentimiento (por lo menos en este material) los humildes y pobres de corazón, sujetos a todo el mundo, pacientes, sufridos, pacíficos, sosegados y dignos de grandísimo amor y compasión. ${ }^{26}$

Es el indio también magnánimo, "liberal", hospitalario en extremo. Da y presta cuanto tiene con espíritu sano y abierto, siendo pobre. Por esta razón el valor de su dádiva es mucho mayor que si fuese rico. Le dice el obispo al Rey: "No parece, Señor, que siendo tan pobres puedan ser 


\section{UNA VISIÓN DEL INDIO MEXICANO}

liberales los indios, (pero) ...es constante que son liberalísimos, como si fueran ricos. Porque como quiera que esta virtud no la hace mayor la materia sino el deseo, y en un príncipe suele ser menos dar una ciudad que en un pobre cuatro reales... Jesucristo Señor nuestro a la viejecita que ofreció al templo dos blancas alabó más que a otros que con menos afecto dieron muy grandes limosnas: así los indios... si tienen dos puñados de maíz, con gran gusto dan el uno a quien le pide. A todas horas están abiertas sus casas para hospedar y ayudar a quien los ha menester." 27

La "parsimonia del indio" la orienta el Visitador de la Nueva España sobre todo a su frugalidad en la comida y a la manera de comportarse en ella. A pesar de la poca comida, la resistencia a los trabajos, fatigas y caminatas es mucha: "...de esta parsimonia en el comer resulta que son grandes sufridores de trabajos; porque a un indio, para andar todo un día le bastan seis tortillas con la agua que halla en los caminos... 28 "El sustento ordinario del indio... es un poco de maíz reducido a tortillas y en una olla echan una poca de agua y chile y la ponen en una hortera de barro o madera, y mojando la tortilla en el agua y chile, con esta comida se sustentan. Al comer, asisten con grandísima modestia, silencio, grande orden y con mucho espacio, porque si son veinte a la mesa, no se verá que dos pongan a un tiempo la mano en el plato y cada uno humedece su corteza con mucho comedimiento, y con una templanza admirable prosiguen despacio con su comida." ${ }^{29}$ He ahí la "parsimonia", actitud más interior y profunda que una simple frugalidad exterior... El agua, las tortillas y el chile... el alimento secular del mexicano pobre.

A partir de ejemplos concretos, tomados de manera principal de las condiciones a las que los indios eran sometidos desde el punto de vista fiscal, de la administración de la justicia, de las disposiciones sobre el recogimiento en aldeas y ciudades, y en los trabajos en beneficio de la comunidad, profundiza Palafox sobre la obediencia que el indio muestra: "Aunque en todas las virtudes son admirables los indios, en ninguna más que en la obediencia, porque como ésta es hija de la humildad y ellos son

${ }^{27} 78$ s. Cita del evangelio, Lc. $21,2$.

${ }^{28} 81$.

2981 . 


\section{Manuel Olimón}

tan humildes y mansos de corazón, son obedientísimos... no se les oye una queja ni un suspiro; insensibles no al conocimiento de la pena ni dolor, que bien conocen y ponderan, sino a su manifestación, ira, furor o impaciencia." ${ }^{30}$

\section{El indio discreto, agudo, cortés e industrioso}

Conforme avanza el texto que leemos y comentamos, avanza la convicción de la solidez interior del indio mexicano, del valor encerrado en su apariencia taciturna.

De la agudeza del ingenio de los naturales, de su capacidad para las ciencias, las artes y los estudios especualtivos habían hablado ya, durante el siglo XVI los misioneros pioneros y habría de hablar más ampliamente, en el siglo XVIII el Padre Francisco Javier Clavijero. ${ }^{31}$ Palafox observa también la profunda y discreta elegancia en el pensar y el expresar oralmente del mexicano: "Son despiertos en discurrir y muy elegantes al hablar... andando por la Nueva España visitando, he llegado a algunos lugares donde los indios me han dado la bienvenida con unas pláticas no sólo bien concertadas, sino tan elegantes y persuasivas que me dejaban admirado." 32

Expone su juicio: "...no les falta entendimiento, antes, lo tienen muy despierto, y no sólo para lo práctico, sino para lo especulativo, moral y teológico." ${ }^{33}$ Ejemplifica con amplitud, narrando acontecimientos concretos de su experiencia, la agudeza, prontitud e industriosidad de los indios. ${ }^{34}$ Reitera la presencia de la humildad en el ser indígena, ampliando su radio de acción hacia lo que denomina "cortesía, silencio y maña del indio": 35 "La cortesía -escribe penetrando en el corazón del indio

${ }^{30} 82$.

${ }^{31}$ En su Historia antigua de México, I disertación. Cf. mi trabajo: Dos aspectos de la cultura mexicana en el siglo XVII, Ef Mex 3/8 (1985), 21-80 (74-79).

3283.

3383.

${ }^{34} \mathrm{Cf} .85-87$.

3591. 


\section{UNA VISIÓN DEL INDIO MEXICANO}

mexicano, de su peculiar estilo de relación humana- es grandísima, porque todos ellos son muy observantes en las ceremonias de reverencia y veneración a los superiores y no se verá ninguno que deje de estar atentísimo en este cuidado." ${ }^{36}$

Le vale un elogio sumario la unión de tantas virtudes en el indio: "No conocen jactancia ni vanagloria, sino que aunque hagan excelentemente una cosa y con destreza, no hacen más cuenta y estimación que si no hubieran obrado cosa alguna o la hubiera hecho un vecino." ${ }^{137}$ Encuentra en el trasfondo de la silenciosa y fina cortesía indígena, de su "maña", la buena educación y el arraigado respeto que se cultivaban en la formación de antaño. Parece que hubieran oído los consejos de los "viejos pláticos" a los que se refiere Fray Bernardino de Sahagún: ${ }^{38}$ "Tienen mucha reverencia los plebeyos a los nobles entre sí, y los mozos a los viejos; éstos son muy templados y se precian de saber y "enseñar a los demás, y ordinariamente enseñan a los niños y niñas a rezar, y no se desprecian de ello, por nobles y grandes que sean. Muchos de estos viejos nobles son amigos de saber sucesos y acaecimientos públicos..." ${ }^{39}$

\section{Paréntesis negativo. La opinión de Sigüenza y Góngora}

Como contraste a la favorable -alguno diría favorabilísima- opinión palafoxiana sobre el indio de México, podríamos presentar la de Don Carlos de Sigüenza y Góngora en su Alboroto y motín de los indios de México, fechado en $1692 .{ }^{40}$

Impactado por el alboroto que se escenificó en la ciudad de México el 8 de junio del año citado, no solamente lo describió con vivos colores, sino que, haciendo uso de todos los recursos dramáticos de su barroco

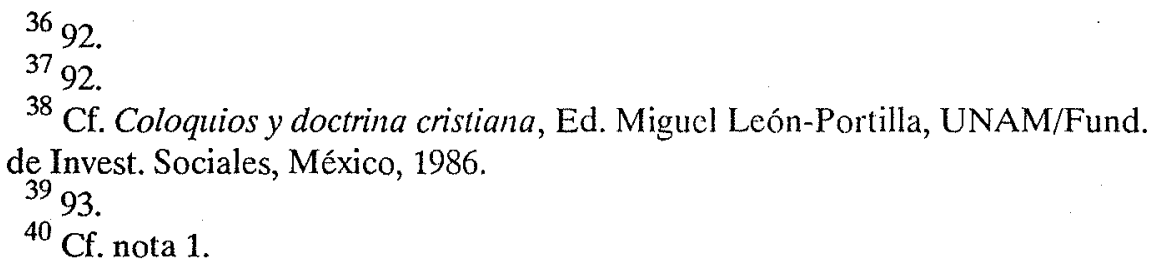


Manuel Olimón

lenguaje, expresó su opinión bastante desfavorable acerca de la intrincada y explosiva composición de la sociedad novohispana y su juicio sobre el "odio a los españoles" y la afición de los indios a las bebidas "espirituosas", entre las que destacaba el pulque.

Retrata el tumulto del cual fue testigo al menos en parte: "Abrí las ventanas a toda prisa y, viendo que corría hacia la plaza infinita gente, a medio vestir y casi corriendo, entre los que iban gritando: "iMuera el virrey y el corregidor, que tienen atravesado el maíz y nos matan de hambre!", me fuí a ella. Llegué en un instante a la esquina de Providencia y, sin atreverme a pasar adelante, me quedé atónito. Era tan extremo tanta gente, no sólo de indios, sino de todas castas, tan desentonados los gritos y el alarido, tan espesa la tempestad de piedras...unos tremolaban sus mantas como banderas y otros arrojaban al aire sus sombreros y burlaban otros; a todos les administraban piedras las indias con diligencia extraña." 41

Le parece que, durante la noche anterior se había celebrado una conjura de indios para causar el gran tumulto y, con él, un inmenso daño a la república. Afirma: "¿Quién podrá decir con toda verdad los discursos en que gastarían los indios toda la noche? Creo que, instigándolos las indias y calentándoles el pulque, sería el primero quitarle la vida, luego al día siguiente, al señor virrey; quemarle el palacio sería el segundo; hacerse señores de la ciudad y robarlo todo, y quizá otras peores iniquidades, los consiguientes. Y esto sin tener otras armas que las del desprecio de su propia vida, que les da el pulque, y la advertencia del culpabilísimo descuido con que vivimos entre tanta plebe, al mismo tiempo que presumimos de formidables. iOjalá no se hubiera verificado, y muy a nuestra costa en el caso presente, esta verdad, y ojalá quiera Dios abrirnos los ojos o cerrarle los suyos de aquí adelante!" 42

"Vivir entre tanta plebe", le parece a Don Carlos un terrible mal, que de alguna forma habría que evitar. Pasa revista, mediante ese curioso desfile de palabras que durante la época colonial se acuñaron para describir las razas del mosaico mexicano, a toda la ralea de miembros de 41 Alboroto, 197. Citaré de acuerdo a la edición de 1986 y sólo la página.
42 191. 


\section{UNA VISIÓN DEL INDIO MEXICANO}

esa pintoresca y explosiva sociedad, participantes en el "alboroto y motín" de la octava de Corpus Christi de 1692: "...siendo plebe tan en extremo plebe, que sólo ella lo puede ser de la que se reputare la más infame, y lo es de todas las plebes, por componerse de indios, de negros criollos y bozales de diferentes naciones, de chinos, de mulatos, de moriscos, de mestizos, de zambaigos, de lobos y también de españoles que, en declarándose zaramullos (que es lo mismo que pícaros, chulos y arrebatacapas) y degenerando de sus obligaciones, son los peores entre esta ruin canalla."

No se le ocurre a nuestro escritor preguntarse el porqué de esas situaciones, las cuales, sin duda, origen tenían en un desorden de estructuras agravado por la presencia de la autoridad y las estructuras sociales españolas. La causa le parece encontrarla en la ingratitud, el abuso y la presunción de los indios frente a la magnanimidad de un virrey que, por : medio de esfuerzos extraordinarios había logrado superar una crisis agrícola distribuyendo maíz en abundancia. El juicio que expresa acerca de los indígenas es tajante: "...gente la más ingrata, desconocida, quejumbrosa e inquieta que Dios creó, la más favorecida con privilegios y a cuyo abrigo se arroja a iniquidades y sinrazones y las consigue." 44 "A medida del dinero que les sobraba, se gastaba en pulque, y sabiendo de sus mujeres el que en la compra del maíz las anteponían aun a los españoles, comenzaron a presumir en las pulquerías ser efecto del miedo que les teníamos, semejante ocasión. ${ }^{45}$

La superstición y sus instrumentos, estaban también como señales del odio que se incubaba hacia los españoles: "...Mucho tiempo antes de ir abriendo la acequia nueva... se sacó debajo de la puente de Alvarado, infinidad de cosillas supersticiosas. Halláronse muchísimos cantarillos y ollitas que olían a pulque y mayor número de muñecos o figurillas de barro, y de españoles todas y atravesadas con cuchillos y lanzas que formaron del mismo barro, o con señales de sangre en los cuellos, como

\footnotetext{
43181.

44184 .

45185 s.
} 


\section{Manuel Olimón}

degollados... prueba real de lo que en extremo nos aborrecen los indios y muestra de lo que desean con ansia a los españoles.. ${ }^{46}$

La manera de opinar de Sigüenza y Góngora, hombre "moderno" para su tiempo, puede tener como base la experiencia, muy distinta a la de Palafox, del indio citadino, obligado a convivvir en un ambiente hostil con toda una gama diferenciada y distante de castas, razas y condiciones de vida. El indio rural, el de los extensos campos mexicanos visitados por el obispo de la Angelópolis, podía desplegar con mucha mayor amplitud su bondad natural y moderar más, llevando una vida con menores presiones, la inclinación a la pereza, a la bebida y al alboroto.

Aunque el choque psicológico del motín de junio de 1692 puede explicar el tono excesivamente riguroso del sabio mexicano, sus opiniones ayudan mucho para descubrir un perfil más matizado del indio sometido durante el siglo XVII novohispano, tan fascinante como complejo.

\section{Los vicios del indio vistos por Palafox}

"Los indios generalmente son honestos, y si no es que la turbación de los sentidos por las bebidas de raíces a las que son inclinados los arrebate, en las demás ocasiones proceden con grande modestia y circunspección." $^{47}$

En tres vicios, "sensualidad, gula y pereza, ...suelen incurrir los indios." 48 De acuerdo al obispo de Puebla de los Ángeles, aun con ser inclinados a ellos, "no puede negarse que son más templados que otras naciones con quien no deseo hacer comparación, ni es necesario." ${ }^{49}$

Expone el mal y propone el remedio: "Y así este primer vicio de la sensualidad se reduce en los indios frágiles al primero de gula, en el cual dejan de incurrir todos los indios en cuanto al comer, porque son

\footnotetext{
${ }^{46} 186 \mathrm{~s}$.

${ }^{47}$ De la naturaleza del indio, 79.

4871.

4971 .
} 


\section{UNA VISIÓN DEL INDIO MEXICANO}

templadísimos. Y en cuanto al beber es certísimo que se enmendarían fácilmente si todos los pastores de sus almas y los alcaldes mayores pusiesen en ello cuidado especial para reformarlos, como lo hacen algunos." 50

La conclusión con la cual, casi al pie de su firma como "El Obispo de la Puebla de los Ángeles", Palafox y Mendoza rubrica su petición de protección al Rey, denuncia la negligencia y falta de apoyo de las autoridades asentadas en el territorio de la Nueva España, como fomentadoras de la prolongación de los males, que deben ser remediados con prontitud para bien tanto de España como de América.

Vale la pena hacer una cita extensa (la última del presente trabajo), elocuente en sí misma: "...Y también puedo asegurar dos cosas. La primera: que si entre ellos hay algunos ladrones, son los que se han criado y viven con los que no son indios, sino entre nosotros y otras naciones de Europa. Y raras veces hurtan los indios, que no los guíen, encubran, promuevan y guarden las espaldas otros de otras naciones, y lo mismo digo cuando incurren en los demás vicios.

La segunda: que cuanto mira a estas bebidas, que es su mayor fealdad, las dejaran fácilmente los indios si muchos superiores a quienes toca, cuidaran la tercia parte de quitarles ese vicio que otros cuidan de promoverlos a él. Pero como sobre el pulque, "vingui", tepache y otras bebidas impuras ha puesto la codicia su tributo, y la bebida del indio es la comida del juez, crece en el miserable la relajación al paso que en el rico la codicia.

Sin que pueda dudarse, Señor, que de la manera que debe la América a la Corona y católicas armas de Vuestra Majestad y a su esclarecida piedad, y de sus gloriosos antecesores, el haber desterrado de ella la idolatría y el comer carne humana y otros abominables y nefandos vicios que frecuentemente acompañan a la ciega gentilidad, le debería también, si quisiesen los ministros inferiores el desterrar de los indios este vicio, el cual, respecto de los otros es ligero y mucho menos vehemente para defenderse en él, por suplirse el beber estas bebidas los indios con otras mucho más sabrosas, que son lícitas. 
Manuel Olimón

Con que este defecto en una naturaleza como la humana, tan llena de imperfecciones no hace que los indios desmerezcan la gracia y amparo real de Vuestra Majestad y su conmiseración y celo, mandar que se ejecuten eficazmente sus santas y religiosas leyes..." 51

\section{Una tarea de luz}

Nada mejor para penetrar en la entraña de la tarea evangelizadora en cualquier época de la historia, que acudir a los testimonios de quienes, en el ejercicio de su misión y de su responsabilidad, han retratado a los sujetos a los que ha de dirigirse el verbo fecundante.

Al tejer con estas abundantes y creo que jugosas citas de ese siglo tan distante y tan nuestro que es el XVII, una red para pescar, hemos obtenido -o al menos así me parece- algo más que la recuperación organizada de datos estériles y rígidos. El indio de México, el que aprendió a crecer en la cercanía de las flores y en la alegría de los cantos, surcó su rostro con la señal adusta de un yugo incomprendido después del "trauma de la conquista".

La fervorosa y penetrante mirada de Palafox, nos ayuda a conocer a ese indio de entonces y quizá también al de ahora, casi perdido en el inmenso piélago del moderno anonimato y de la identidad cuestionada y acosada. Nos da a conocer igualmente su perfil de pastor, más fino, recio y orientado hacia la santidad de lo que podemos pensar en un primer momento.

El "paréntesis negativo" del "alboroto y motín" tal como lo dibujó Don Carlos de Sigüenza y Góngora, es apenas un asomo a la tremenda problemática social, a la injusticia y a la violencia "institucional" de aquel tiempo aparentemente tranquilo y apacible, de aquella sociedad todavía poco conocida.

La tarea de evangelizar es tarea de siempre, no de un siglo o de otro. Lanzarse a conocer y reconocer el pasado, lanzarse a la busca de raíces,

$5196 \mathrm{~s}$. 


\section{UNA VISIÓN DEL INDIO MEXICANO}

es tarea no sólo de historiadores, sino de hombres conscientes y con deseo de vivir con un sentido en el horizonte.

De la vida de la Nueva España tenemos, como fuentes para el conocimiento histórico y vital, la piedra de monumentos y catedrales, la preciosa y familiar pintura y escultura y la palabra escrita, que reposa en abundancia esperando todavía lectores e intérpretes. Si la piedra colonial es todavía lámpara que lanza destellos, si la pintura colonial es espejo donde aún puede mirarse nuestra emoción y nuestro espíritu, la palabra escrita colonial es consejo vivo e incentivo para un mayor compromiso con el futuro.

El servicio que he sentido deber realizar hoy en estas líneas que terminan sea, trocado en gracia, aliento y luz. 